\title{
O Livro Didático de Matemática no Ensino Fundamental do Cariri (1960-1980): Uma Pesquisa Documental
}

\author{
Margarida Maria de Souza Santos Albuquerque ${ }^{1}$; Ariza Maria Rocha ${ }^{2}$
}

Resumo: Esta comunicação tem o intuito de analisar o Livro Didático de Matemática no Ensino Fundamental (1960-1980). Para tanto, nos nortearemos pela seguinte indagação: Quais eram os conteúdos dos livros didáticos de matemática empregados no processo de aprendizagem dos educandos? Como suporte teórico-metodológico utilizaremos a pesquisa documental. Para efetuar a análise tomamos as seguintes categorias: a) prefácio; b) formatação; c) ilustrações e imagens; d) conteúdo pedagógico; e) os autores e suas formações acadêmicas. Esperamos com este estudo contribuir para o ensino da matemática no Cariri.

Palavras-chaves: Livro didático. Ensino-aprendizagem da matemática. Pesquisa documental.

\section{Math Textbook On The Fundamental Cariri Education (1960-1980): A Documentary Survey}

\begin{abstract}
This paper aims to analyze the Didactic Book of Mathematics in Basic Education (1960-1980). To do so, we will be guided by the following question: What were the contents of the mathematics textbooks used in the students' learning process? As a theoretical-methodological support we will use documentary research. To carry out the analysis we take the following categories: a) preface; b) formatting; c) illustrations and images; d) pedagogical content; e) the authors and their academic backgrounds. We hope with this study to contribute to the teaching of mathematics in Cariri.
\end{abstract}

Keywords: Textbook. Teaching-learning of mathematics. Documentary research.

\section{Introdução}

O livro didático de matemática desempenha uma função muito importante no processo de ensino-aprendizagem. Ao longo dos anos os livros vêm sofrendo modificações relevantes para a melhoria da aprendizagem dos educandos. Fato que o coloca em posição de destaque nas pesquisas científicas, sendo objeto de análise e muitas vezes o principal suporte pedagógico utilizado pelo professor em sala de aula.

\footnotetext{
${ }^{1}$ Graduação em Matemática pela Universidade Regional do Cariri, Especialista em Gestão Escolar pela Faculdade de Juazeiro do Norte, Especialista em Matemática do Ensino Médio pela Universidade Regional do Cariri e Especialista em Psicopedagogia Clínica e Institucional pela Faculdade de Juazeiro do Norte - CE. Aluna do Programa de Mestrado Profissional em Educação - MPEDU da URCA. Contato: margaridamssa@gmail.com;

${ }^{2}$ Pós-doutorado em História pela Faculdade de Letras/ Universidade de Lisboa-FLUL Doutora em Educação Brasileira, Universidade Federal do Ceará-UFC. Docente permanente no Mestrado Profissional em Educação da URCA.

Contato: ariza.rocha@urca.br;
} 
Durante muito tempo, pesquisadores e docentes de matemática, perguntam-se como os conteúdos dos livros de matemática vêm mudando com o passar dos anos e como estas mudanças afetam a aprendizagem dos educandos? Visto que para muitos educadores este é o único recurso pedagógico que os orienta/direcionam na elaboração do planejamento de suas aulas, indicando como e quais os conteúdos curriculares devem ser trabalhados em cada série/ano.

Com o intuito de entendermos como as mudanças nos conteúdos dos livros didáticos aconteceram e como estas afetam o processo de ensino-aprendizagem presente, faz-se necessário analisarmos o contexto histórico do recorte temporal (1960-1980) em estudo, ou seja, tentaremos entender o presente partindo de uma abordagem histórica que nos forneça elementos suficientes para refletirmos e contribuir com o ensino da matemática.

Assim, este artigo divide-se nos seguintes tópicos: O livro didático e o processo de ensino-aprendizagem e O livro didático de Matemática: Um documento de pesquisa. Dessa forma, esperamos contribuir para a melhoria do processo de ensino-aprendizagem dos educandos na disciplina de matemática e proporcionar aos educadores fundamentação teórica, que os auxiliem a resinificarem sua prática pedagógica mediada pela utilização do livro didático.

\section{O Livro Didático e o Processo de Ensino-Aprendizagem}

O homem sempre sentiu a necessidade de registrar fatos ou acontecimentos para marcar determinado período e poder repassá-los para as próximas gerações. Devido essa necessidade é que durante a História da humanidade os registros foram acontecendo em diversos materiais, de acordo com a época. Por exemplo, na Antiguidade que o homem grava os acontecimentos em pedras ou tábuas de argilas. Encontrando, assim, formas de perpetuar os fatos históricos.

Como afirma Alves (2005, p.21) "O livro fez com que a palavra escrita permanecesse viva, vencendo o tempo, conquistando o espaço, permitindo à humanidade o contato desde os pensamentos de Sócrates (470 - 399 a.C.) até Popper (1902-1994)”. Assim, a história da origem dos livros confunde-se com a própria História da humanidade, devido à forma como os homens 
registraram os fatos ocorridos em um determinado momento e selecionaram o que é relevante para ser passado de uma geração para outra.

Mas, o que vem a ser um livro? O termo "livro" surge na língua portuguesa no ano de 1013, de acordo com Houaiss (2001, p.1774), o livro é uma "coleção de folhas de papel, impressas ou não, cortadas, dobradas e reunidas em cadernos cujos dorsos são unidos por meio de cola, costura, etc., formando um volume que se recobre com capa resistente". O autor, acima citado, faz referência a materialidade dos livros da mesma forma das obras físicas que encontramos atualmente. Porém há muito mais, além da materialidade para Claret $(2002$, p.7) “o livro é um produto industrial. Mas também é mais do que um simples produto. O primeiro conceito que deveríamos reter é o de que o livro como objeto é o veículo, o suporte de uma informação. O livro é uma das mais revolucionárias invenções do homem".

Por tanto, quando o Claret (2002) coloca o livro como suporte de uma informação e uma invenção revolucionária, está implícito que os livros estão carregados de intencionalidades e ideologias de quem os produziram de acordo com o contexto histórico no qual está inserido, para o mesmo autor, no contexto atual "o livro pode ser considerado como uma mercadoria cultural, com maior ou menor significado no contexto socioeconômico em que é publicado" (IDEM, 2002, p.8).

Com relação ao livro didático, propriamente dito, Houaiss (2001) o define como "aquele adotado em estabelecimentos de ensino, cujo texto se enquadra nas exigências do programa escolar". Para conceituar o livro didático de forma mais ampla utilizaremos Batista (1999, p.534) que o define como "aquele livro ou impresso empregado pela escola, para desenvolvimento de um processo de ensino ou de formação".

Por tanto, desde o princípio, o livro didático é uma obra criada intencionalmente para ser trabalhada nas ações pedagógicas que são desenvolvidas nos estabelecimentos de ensino, sejam estes públicos ou privados. Assim, para Gatti Júnior,

\footnotetext{
Sua origem está na cultura escolar, mesmo antes da invenção da imprensa no final do século XV. Na época em que os livros eram raros, os próprios estudantes universitários europeus produziam seus cadernos de textos. Com a imprensa, os livros tornaram-se os primeiros produtos feitos em série e, ao longo do tempo a concepção do livro como "fiel depositário das verdades científicas universais" foi se solidificando (GATTI JÚNIOR, 2004, p.36).
}

O livro didático por ser um importante instrumento pedagógico, sempre, exerceu um papel de destaque nas Políticas Educacionais Brasileiras. A história da origem do livro didático 
no Brasil data de 1929 com a criação do Instituto Nacional do Livro (INL), que tinha o intuito de legitimar o livro didático nacional.

Somente em 1934, no governo do presidente Vargas, iniciou-se a elaboração de um dicionário nacional e uma enciclopédia, havendo considerável aumento no número de bibliotecas públicas. Desde a sua origem, o livro didático, tem sido objeto de interesse do governo, o qual fiscaliza a elaboração das obras e controla o que vai ser trabalhado dentro dos estabelecimentos de ensino.

\begin{abstract}
O ministro do Ministério Educação e Saúde, Gustavo Capanema, durante o Estado Novo brasileiro, sugeriu a Getúlio Vargas a criação de decreto-lei para fiscalizar a elaboração dos livros didáticos [sic]. A comissão foi criada em 1938 e 'estabelecia que, a partir de $1^{\circ}$ de janeiro de 1940 , nenhum livro didático poderia ser adotado no ensino das escolas pré-primárias, primárias, normais, profissionais, e secundárias no país sem a autorização prévia do Ministério da Educação e Saúde (FERREIRA, 2008, p.38).
\end{abstract}

Nesse período já havia uma preocupação com a distribuição dos livros e várias governantes buscaram formas de solucionar os desafios que surgiam durante o processo de distribuição e produção.

Há registros que mostram que esse movimento de produção e distribuição no território brasileiro foi bem conturbado em alguns momentos históricos, a saber no: Período do Regime Militar (1964-1985), fase que contempla o contexto histórico do estudo em questão, analise dos livros didáticos de matemática (1960-1980).

No início, desse período, em 1964 aconteceu o Golpe de Estado. A ditadura Militar resolve reformar à educação a seu modo, aplica-se o modelo bancário à educação, pagamento de cadeiras e sistemas de crédito, matrícula por disciplina, vestibular classificatório, regime de créditos, sistema integrado de pós-graduação, privatização do ensino, ou seja, aconteceu uma desmobilização da educação que era embasada em uma pedagogia no mínimo repressora.

A principal interferência a ser destacada é sem dúvida a paulatina e a decisiva transferência de questões políticas em questões meramente técnicas, período de maior produtividade como prioridade. Dessa forma, percebe-se nos currículos escolares as tendências ideológicas da doutrina de segurança nacional, e as ações fiscalizadoras do Estado com relação ao livro didático se tornam mais intensas.

Dessa forma, surge à censura e falta de liberdade nas obras que seriam publicadas como afirma Bezerra e Luca (2006, p. 30). 
Em 1966, sob a égide da ditadura militar foi criada a Comissão do LivroTécnico e Livro Didático (COLTED), cuja função era coordenar a produção, edição e distribuição do livro didático. Para assegurar recursos governamentais, contou-se com o financiamento proveniente do acordo MEC - USAID (United States Agency for Internacional Development). $\mathrm{O}$ aporte de recursos públicos garantiu a continuidade do livro didático que, a partir de então, ocupou lugar relevante nas preocupações do Estado brasileiro que, mais uma vez, pretendia ter o controle sobre o que e como se ensinava.

Nesse período percebe-se que houve um aumento notório na comunidade escolar e na publicação de livros didáticos. Devido o poder autoritário do Estado que regulava a obrigatoriedade do acesso à escola, com interesses específicos emanados do Regime Militar.

A questão da compra e distribuição de livros didáticos recebeu tratamento específico do poder público em contextos diferenciados — 1966, 1971 e 1976 —, todos marcados, porém, pela censura e ausência de liberdades democráticas. De outra parte, esse momento foi marcado pela progressiva ampliação da população escolar, em um movimento de massificação do ensino cujas consequências [sic], sob o ponto de vista da qualidade, acabariam por deixar marcas indeléveis no sistema público de ensino e que persistem como o seu maior desafio. Neste contexto particular, destaca-se o peso da interferência de pressões e interesses econômicos sobre a história ensinada, na medida em que os governos militares estimularam, por meio de incentivos fiscais, investimentos no setor editorial e no parque gráfico nacional que exerceram papel importante no processo de massificação do uso do livro didático no Brasil. Cabe destacar que a associação entre os agentes culturais e o Estado autoritário transcendeu a organização do mercado consumidor da produção didática e envolveu relações de caráter político-ideológico, cujas repercussões sobre o conteúdo dos livros didáticos foram marcantes, sobretudo pela perspectiva de civismo presente na grande maioria das obras, bem como pelo estímulo a uma determinada forma de conduta do indivíduo na esfera coletiva (MIRANDA, 2004, p.3).

Dessa forma o livro didático passa a ser instrumento de controle do acesso ao conhecimento expressando os interesses do governo, ou seja, tornou-se um dos instrumentos de repressão do Estado, que por sua vez viabilizava uma distribuição intensa fazendo chegar às mãos da população as obras adotadas.

Assim, o livro passou a ser foco de interesses não só dos equipamentos de ensinos e do governo, mas também do mercado editorial. Passando por várias mudanças na década de 70 , principalmente no ensino fundamenta havendo a renovação das obras.

Conforme, afirma Gatti Júnior (2004) essas mudanças,

Possibilita a melhoria do padrão estético dos mesmos. O uso das cores é uma marca dos livros destinados ao ensino fundamental, em que existem mais ilustrações, boxes e outros recursos de edição e formatação do texto. 
Os livros destinados ao ensino médio eram à época mais despojados que os primeiros. Neles, o privilégio sempre esteve no texto escrito e não nos filigranas e ilustrações (GATTI JÚNIOR, 2004, p. 106).

O autor acima citado expressa as mudanças ocorridas no livro, considerando vários aspectos que eram relevantes para melhoria da qualidade das obras, inclusive a formatação e as ilustrações, as quais são valorizadas até hoje. Fato que provocou um crescente interesse das editoras e do governo, movimentando dessa maneira o mercado editorial.

Portanto, esse momento culminou com a legislação do Livro Didático que foi promulgada em 1985 com a aprovação do Plano Nacional do Livro Didático (PNLD) e que vigora até hoje, juntamente com o Programa Nacional do Livro Didático para o Ensino Médio (PNLEM) que foi criado em 2004 e o Programa Nacional do Livro Didático para Alfabetização de Jovens e Adultos (PNLA) que teve início em 2007.

Conforme exposto, percebemos que o Livro Didático com o passar dos anos vem sofrendo alterações relevantes, no que diz respeito à materialidade, à fiscalização e controle das obras. Sendo objeto de estudo devido o importante papel que ocupa como suporte pedagógico para o professor na sua prática diária, por muitas veze, é o único recurso pedagógico.

Dessa forma, constatamos que o processo de ensino aprendizagem que prevalece é embasado no método tradicional, no qual a exposição de conteúdo via professor e o livro didático são os principais recursos utilizados em sala de aula.

Se na pedagogia tradicional a iniciativa cabia no professor, que era, ao mesmo tempo, o sujeito do processo, o elemento decisivo e decisório; e se na pedagogia nova a iniciativa se desloca para o aluno, situando-se o Nervo da ação educativa na relação professor-aluno, relação interpessoal, intersubjetiva (SAVIANI, 2008, p. 382).

Conforme o autor, acima citado, na Pedagogia Tradicional o centro das atenções era o professor, que era visto como detentor do saber, na Pedagogia Nova o foco passa a ser o aluno e a ação educativa acontece na relação professor x aluno, que continua sendo mediada pela utilização do livro didático como instrumento de aprendizagem.

Fato que, também, foi evidenciado pelo Ministério de Educação (MEC) ao reforçar que o livro didático ocupa papel de destaque no processo de ensino-aprendizagem.

Há situações, em que o livro didático tem ocupado papel dominante no ensino. Nestes casos, convém lembrar que, apesar de toda a sua importância este livro não deve ser o único suporte do professor. É sempre desejável buscar enriquecê-lo com outras fontes, afim de ampliar ou aprimorar o conteúdo que ele traz e, acima de tudo, adequálos ao grupo de alunos que o utilizam. (BRASIL, 2010, p.16). 
De fato o livro didático é importante para o processo ensino aprendizagem, sendo instrumento que facilita a aprendizagem e torna as informações acessíveis a todos os educando. O acesso aos livros é viabilizado através do Programa Nacional do Livro Didático (PNLD) que é de responsabilidade do Ministério da Educação (MEC), o qual reforça que o livro didático tem ocupado papel principal nos estabelecimentos de ensino, sendo o único instrumento pedagógico que professor utiliza prioritariamente.

Os problemas do nosso sistema educacional são muitos e complexos, porém algumas Políticas Educacionais Brasileiras geram ações que já são desenvolvidas e que tem contribuído significativamente para a melhoria do ensino como pode ser destacadas, a exemplo do Programa Nacional do Livro Didático (PNLD), o qual consiste em:

\footnotetext{
Prover as escolas públicas de ensino fundamental e médio com livros didáticos e acervos de obras literárias, obras complementares e dicionários. O PNLD é executado em ciclos trienais alternados. Assim a cada ano o FNDE adquire e distribui livros para todos os alunos de determinada etapa de ensino e repõe e completa os livros reutilizáveis para outras etapas (BRASIL, 2016).
}

Dessa forma faz chegar às mãos de todos os alunos da rede pública os livros didáticos, os quais são criteriosamente selecionados, desta maneira, os livros didáticos oferecidos pelo governo contêm um selo de qualidade com poucos erros grosseiros e consistentes em sua proposta metodológica, ou seja, além da oferta a equipe pedagógica do Ministério da Educação - MEC se preocupa também com a qualidade dos livros, ofertando assim um material de boa qualidade.

É bem verdade que serão necessários alguns ajustes, pois o grande desafio atual no Brasil é o alto custo dos livros didáticos, os interesses políticos e a censura a conteúdos. Mas a iniciativa é muito pertinente, pois a maioria das escolas públicas da nossa região já tem livro didático à disposição dos alunos, ou seja, o objetivo de levar conhecimento aos alunos das escolas públicas está sendo alcançado com o PNLD.

\section{O Livro Didático de Matemática: um Documento de Pesquisa}

A necessidade da pesquisa surge quando nos deparamos com um problema e nos sentimos pressionados a buscar as possíveis soluções. Segundo Fachin (2006, p. 139) "o que 
nos induz a buscar solução para o problema constitui a pesquisa propriamente dita”. Para tanto, necessitamos de métodos e estratégias específicas, a fim de refletir, analisar, construir e ressignificar os conhecimentos com relação ao objeto de estudo e como este se relaciona com contexto histórico, no qual está inserido.

Adotamos a pesquisa documental como estratégia metodológica da dissertação que tem como título: O livro didático de matemática no ensino fundamental do cariri (1960-1980): Uma pesquisa documental. Tendo como objeto de estudo sete livros didáticos de matemática do período supracitado.

Por tanto, utilizamos este método com o intuito de analisarmos como a álgebra foi trabalhada nos livros selecionados, focando os conteúdos de Função Polinomial do $1^{\circ}$ Grau e Teoria Elementar dos Conjuntos, evidenciando quais tendências pedagógicas influenciaram os autores na elaboração das obras e quais as suas formações acadêmicas. Assim, a pesquisa em estudo é para a pesquisadora o resultado de estudos e de sua atitude diante da vida, embutindo no processo a sua visão de mundo e a contribuição de novos conhecimentos para aperfeiçoar o processo de ensino aprendizagem da matemática através do livro didático.

Diante do exposto, descreveremos a pesquisa documental utilizada na dissertação intitulada "O livro didático de matemática no ensino fundamental do cariri (1960-1980): Uma pesquisa documental", que está sendo produzida no Curso de Mestrado Profissional em Educação da Universidade Regional do Cariri. O objetivo do trabalho é analisar os livros didáticos e o processo de ensino-aprendizagem da matemática no período supracitado.

O recorte temporal definido para análise delimitou o trabalho no período de 1960 a 1980. A data inicial considera a reorganização do ensino no Brasil, com a promulgação da Primeira Lei de Diretrizes e Base da Educação - Lei 4.024/1961 - com o curso ginasial fixado em quatro anos, a organização e evolução da disciplina de matemática através do Movimento da Matemática Moderna, no Brasil, que foi viabilizado, entre outros motivos, pela criação do GEEM (Grupo de Estudos do Ensino de Matemática), em São Paulo no ano de 1961 (BÚRIGO, 1990, p.258) e a fundação, também em 1961, do Comitê Interamericano de Educação Matemática (CIAEM), responsável pelo início do Movimento de Educação Matemática no Brasil.

Consideramos posteriormente a Lei 5.692/1971, que traz mudanças curriculares relevantes para o ensino fundamental e o contexto histórico brasileiro, período do Regime Militar. Ressaltamos, ainda, a promulgação da primeira Legislação do Livro Didático criada 
em 1938 com o Decreto-Lei 1006, que trouxe consigo novas propostas de organização curricular e políticas públicas em relação aos livros didáticos que possivelmente tenham influenciado a edição desses impressos, pois nesse período já se concebia o livro como uma ferramenta pedagógica carregada de concepções políticas e ideológicas, sendo o Estado o censor no uso desse material didático.

Assim, os professores faziam a escolha através de uma relação de obras, previamente selecionadas e regulamentadas pelo Art. 208, Inciso VII da Constituição Federal do Brasil, que trata do dever do Estado com a educação por meio dos programas suplementares de material didático-escolar.

No primeiro momento fizemos um levantamento dos possíveis locais onde poderíamos encontrar os livros que precisaríamos, o principal local foi a Biblioteca Pública Municipal de Juazeiro do Norte-CE, onde encontramos um número significativo de livros do período em estudo, e a Biblioteca de uma escola estadual, nos disponibilizou três livros. Após a identificação dos locais selecionamos as obras e organizamos uma lista com os títulos de todos os livros, seu(s) autor(es) e ano de publicação.

Nesse momento realizamos a leitura dos prefácios e dos sumários das obras, para selecionar os que eram relevantes para pesquisa. Especificamos os conteúdos que serão analisados, que deveriam ser comuns a todos os livros e os anos de publicação (1960-1980). Fazendo as transcrições dos aspectos que eram importantes para a nossa investigação e promovendo a categorização, através das informações que foram analisadas. Em seguida farse-á a análise com base na materialidade das obras, levando em consideração a formatação, as imagens, os tipos de impressões, contextualização e a tendência matemática predominante presente nos conteúdos.

Assim, serão examinados sete livros didáticos do período, com o intuito de obter elementos que nos permitam elaborar possíveis respostas à questão da pesquisa "Como eram os livros didáticos de Matemática no período de 1960 a 1980, utilizados como ferramenta pedagógica no processo de ensino-aprendizagem dos educandos?”.

A metodologia será trabalhada com o intuito de analisar os livros didáticos de Matemática no ensino da álgebra, compreender a trajetória da mesma enquanto disciplina escolar no ensino fundamental através dos conteúdos, enfatizar os fatores que foram determinantes para mudanças, ou não, observadas e quais interferiram nas formulações curriculares desse período. 
De forma complementar abordamos referencial bibliográfico que tratava do contexto histórico do período em estudo, com base em diferentes referenciais teóricos, com o intuito de evidenciar as correntes matemáticas que orientaram a elaboração desses livros didáticos, com suas origens e desdobramentos nas publicações destinadas ao ensino de matemática.

O segundo momento é a análise dos conteúdos dos livros didáticos, que está em andamento, etapa que requer muita cautela e olhar crítico-reflexivo. Fato que possibilita a criação de novas categorias, visto que o pesquisador poderá percebe dados que são relevantes para a sua pesquisa e que não havia categorizado. Portanto, devido à pesquisa está em andamento não é possível fazermos nenhuma consideração final com base na análise dos documentos, pois ainda não terminamos de analisar os conteúdos das obras selecionas.

Vale salientar que adotar a pesquisa documental como metodologia oferece grande vantagem aos pesquisadores, os quais se apropriam de uma parte da História, por meios de documentos e contribuem para a compreensão e formulação de conhecimentos acerca da realidade da sociedade. Por outro lado, temos como desvantagem a falta de cuidados na preservação dos documentos, em vários lugares guardados de formas inadequadas e desorganizadas, alguns com as folhas soltas ou rasgadas, amontoados em um local qualquer e cheio de poeira, dificultando o acesso.

\section{Considerações Finais}

A pesquisa documental é uma ferramenta metodológica que nos permite buscar uma melhor compreensão dos fatos no contexto sócio-histórico, considerando as conjunturas sócioeconômicas e políticas ocorridas em um determinado período e compreender como essas interferem ou não na realidade social.

Por meio do exposto, até o momento, esperamos contribuir a partir da pesquisa documental para a compreensão e transformação da realidade da sociedade, na qual estamos inseridos.

E a utilização do livro didático como objeto de estudo nos possibilita investigar as concepções ideológicas que predominava no processo de ensino no ambiente escolar, ou seja, ver além do que está escrito analisando as tendências pedagógicas que estavam formando os 
educandos daquele período. Daí surgindo indagações com relação aos conteúdos ministrados e discursos, relacionando-os ao contexto histórico da educação brasileira.

Através dos livros escritos buscamos a essência dos discursos e das práticas pedagógicas para tentarmos compreender o que está por trás dos documentos analisados, que interferem ou não na realidade social, e contribuir para (re)construção de conhecimentos no âmbito da educação brasileira.

\section{Referências}

ALVES, A. M. M. Livro didático de matemática: uma abordagem histórica; orientadora, Eliane Teresinha Peres. - Pelotas, 2005. 178f. Disponível em: www.educadores.diadia.pr.gov.br. Acesso em: 04 de novembro de 2017.

BATISTA, A. A. Um objeto variável e instável: textos, impressos e livros didáticos. In: ABREU, Márcia (org.). Leitura, História e História da Leitura. São Paulo: Mercado das Letras, 1999.

BEZERRA, H. G. LUCA, T. R. Em busca da Qualidade PNLD - História - 1996 - 2004. In: SPOSITO, M. E. B (org.). Livros Didáticos de História e Geografia. Avaliação e Pesquisa. São Paulo: Cultura Acadêmica, 2006. p. 27 - 53.

BRASIL. Parâmetro curriculares nacionais: ensino médio. Ministério da Educação. Secretaria de Educação Média e Tecnológica. Brasília: MEC/SEMTEC, 1999. v. 4.

Coleção Explorando o Ensino, v. 17. Ministério da Educação, Secretária da Educação Básica, Brasília, 2010. 248p.

Programa Nacional do Livro Didático (PNLD). 2016. Disponível em: <http://portal.mec.gov.br>. Acesso: 14 nov. 2016.

BÚRIGO, E. Z. Matemática moderna: progresso e democracia na visão de educadores brasileiros nos anos 60. Teoria \& Educação. Porto Alegre: Pannonica, número 2, p. 177 229, 1990.

CLARET, M. Dicionário Filosófico - Voltaire. São Paulo: Martin Claret, 2002.

FACHIN, O. Fundamentos de Metodologias. 5. ed. [rev.] - São Paulo: Saraiva, 2006. P. 210

FERREIRA, R. C. C. A comissão nacional do livro didático durante o estado novo (1937 1945). Assis 2008. 
GATTI JÚNIOR, D. A escrita escolar da história: livro didático e ensino no Brasil. Bauru, SP: Edusc; Uberlândia, MG: Edufu, 2004.

GOMES, R. Análise e interpretação de dados de pesquisa qualitativa. In.: DESLANDES, S. F; MINAYO, M. C. S.(org). Pesquisa social: teoria, método e criatividade. 26 ed. Petrópolis, RJ: Vozes, 2007. P. 108.

HOUAISS, A. Et al. Dicionário Houaiss da Língua Portuguesa. Rio de Janeiro: Objetiva, 2001.

LAKATOS, E.M; MARCONI, M.A. Fundamentos de metodologia científica. 8 ed. São Paulo: Atlas, 2017.

MIRANDA, S. R.; LUCA, T. R. O livro didático de história hoje: um panorama a partir do PNLD. Revista Brasileira de História, São Paulo, v.24, n.48, 2004. Disponível em: http://www.scielo.br/pdf/rbh/v24n48/a06v24n48.pdf/>. Acessado em 25 de novembro de 2017.

PÁDUA, E. M. M. Metodologia da pesquisa: Abordagem teórico-prática. 17 ed. Campinas, SP: Papirus, 2012. 127 páginas. (Coleção Magistério: Formação e Trabalho Pedagógico).

SAVIANI, D. Histórias das Ideias Pedagógicas no Brasil. 2. ed. Campinas/SP: Autores associados, 2008. (Coleção Memória da Educação).

Como citar este artigo (Formato ABNT):

ALBUQUERQUE, Margarida Maria de Souza Santos; ROCHA, Ariza Maria Rocha O Livro Didático de Matemática no Ensino Fundamental do Cariri (1960-1980): Uma Pesquisa Documental. Id on Line Rev.Mult. Psic., 2018, vol.12, n.41, p.649-660. ISSN: 1981-1179.

Recebido: 10/07/2018

Aceito 11/07/2018 